\title{
Differential proteomics analysis of low- and high- grade of astrocytoma using ITRAQ quantification
}

\author{
This article was published in the following Dove Press journal: \\ OncoTargets and Therapy \\ 27 September 2016 \\ Number of times this article has been viewed
}

\author{
Tong Ren ${ }^{1, *}$ \\ Shide Lin $2, *$ \\ Zhongfeng Wang ${ }^{3}$ \\ Aijia Shang ${ }^{4}$ \\ 'Department of Neurosurgery, Beijing \\ Tiantan Hospital, Capital Medical \\ University, Beijing, ${ }^{2}$ Department \\ of Spinal Cord Injury, Institute of \\ Orthopedics and Traumatology of \\ Chinese PLA, General Hospital of \\ Jinan Military Area Command, Jinan, \\ ${ }^{3}$ State Key Laboratory of Medical \\ Neurobiology, Shanghai Medical \\ College, Fudan University, Shanghai, \\ ${ }^{4}$ Department of Neurosurgery, \\ General Hospital of Chinese People's \\ Liberation Army of China, Beijing, \\ People's Republic of China \\ *These authors contributed equally \\ to this work
}

\begin{abstract}
Astrocytoma is one of the most common types of brain tumor, which is histologically and clinically classified into four grades (I-IV): I (pilocytic astrocytoma), II (diffuse astrocytoma), III (anaplastic astrocytoma), and IV (glioblastoma multiforme). A higher grade astrocytoma represents a worse prognosis and is more aggressive. In this study, we compared the differential proteome profile of astrocytoma from grades I to IV. The protein samples from clinical specimens of grades I, II, III, and IV astrocytoma were analyzed by two-dimensional liquid chromatography-tandem mass spectrometry and isobaric tags for relative and absolute quantitation and quantification. A total of 2,190 proteins were identified. Compared to grade I astrocytoma, $173(12.4 \%), 304(14 \%)$, and $462(21.2 \%)$ proteins were aberrantly expressed in grades II, III, and IV, respectively. By bioinformatics analysis, the cell proliferation, invasion, and angiogenesis-related pathways increase from low- to high-grade of astrocytoma. Five differentially expressed proteins were validated by Western blot. Within them, matrix metalloproteinase- 9 and metalloproteinase inhibitor 1 were upregulated in glioblastoma multiforme group; whereas fibulin-2 and -5 were downregulated in grade II/III/IV astrocytoma, and the negative expression was significantly associated with advanced clinical stage. Functional analysis showed that both fibulin-2 and -5 may exert an antitumor effect by inhibiting cell proliferation, in vitro migration/invasion in glioma cells. New molecular biomarkers are likely to be used for accurate classification of astrocytoma and likely to be the target for drug development.
\end{abstract}

Keywords: brain tumor, glioma, astrocytoma, clinical grades, bio-markers, Fibulin-2, Fibulin-5

\section{Introduction}

Astrocytoma is the most common type of brain tumor (glioma) originating in astrocytes, which is a group of star-shaped brain cells located in the cerebrum. Astrocytoma can be categorized into four grades: grade I (pilocytic astrocytoma), II (diffuse astrocytoma), III (anaplastic astrocytoma), and IV (glioblastoma multiforme, GBM). Low clinical grade (grade I or II) astrocytoma has a better prognosis or less aggressive features than higher grade (III or IV) astrocytoma. Grade I astrocytoma are featured as slow growing, benign, and associated with long-term survival of patients, while patients with grade II astrocytoma have a median survival of $\sim 7-8$ years. ${ }^{1-3}$ At the same time, patients with grade III astrocytoma have a median survival of $\sim 2-3$ years, and patients with GBM of only 9-14 months. ${ }^{1-3}$ GBM is the most aggressive astrocytoma and the most common of all primary central nervous system tumors. ${ }^{4}$ Thus it would be valuable to reveal the detailed mechanisms and identify biomarkers/indicators of astrocytoma, especially highly aggressive astrocytoma, that is, GBM.

Until now, multiomics data integration and analysis for astrocytoma data provided more information about astrocytoma pathogenesis. By proteomics analysis, many important signaling pathways, such as receptor tyrosine kinase signaling (including
Correspondence: Aijia Shang Department of Neurosurgery, General Hospital of Chinese PLA, No $28 \mathrm{Fu}$ Xing Road, Haidian District, Beijing City 100853, People's Republic of China

Tel +86 I0 66938240

Fax +861066938240

Email shangaj@I26.com 
epidermal growth factor receptor [EGFR], platelet-derived growth factor receptor, and vascular endothelial growth factor receptor), ${ }^{5,6}$ calcium signaling (including S100 proteins, annexins, integrins, and receptors), mechanistic target of rapamycin (mTOR), Notch or Wnt/ $\beta$-catenin, have been identified that are dysregulated in GBM. ${ }^{3,7,8}$ Some other groups reported that CD90, CD133, and NPM (nucleophosmin) are aberrantly expressed in astrocytoma. ${ }^{9-12}$ Sallinen et $\mathrm{al}^{13}$ used transcriptome analyses and found that various genes related to cell metastasis and angiogenesis were upregulated in astrocytoma. ${ }^{13} \mathrm{He}$ also found that some cell cycle-related genes were downregulated in astrocytoma. Although several potential biomarkers have been identified in astrocytoma, especially in GBM, more accurate candidate biomarkers of astrocytoma with different clinical degrades are required, which could better understand the differentiation between low- or high-grade astrocytoma, and would benefit clinical research and its application.

In this work, we used a proteomic approach to examine the proteomic feature among low- and high-grade astrocytomas. The pooled low- and high-grade astrocytoma protein samples were tryptic digested, labeled by 8-plex isobaric tags for relative and absolute quantitation (iTRAQ) reagents, and then mixed and analyzed by Reversed Phase-Reversed Phase high-performance liquid chromatography tandem mass spectrometry (LC-MS/MS). By iTRAQ quantification, proteins with an over twofold changes were considered as differential proteins. After that, the biological functions and canonical

\section{Pooled astrocytomas tissue samples}

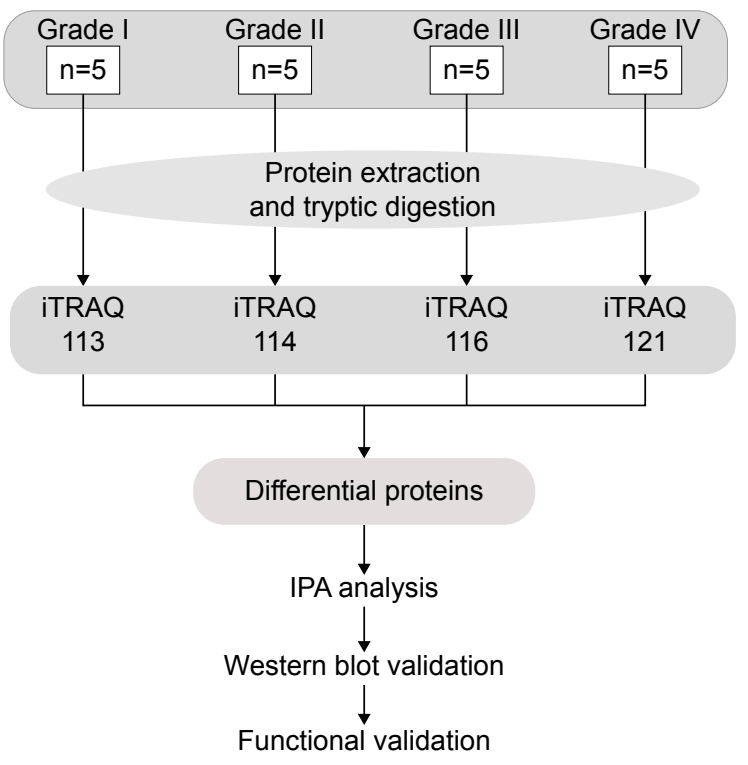

Figure I Work flow of differential proteome analysis of low- to high-grade astrocytomas.

Abbreviations: IPA, ingenuity pathway analysis; iTRAQ, isobaric tags for relative and absolute quantitation. pathways belonging of the differentially presented proteins were annotated by ingenuity pathway analysis (IPA). Then, five candidate proteins were validated in multiple individual samples using Western blot. Furthermore, effects of two candidate biomarkers, fibulin-2 and -5 , on proliferation and metastasis of astrocytoma cells were tested (Figure 1).

\section{Materials and methods Case selection criteria}

The collection of tissues and the study protocol was all approved by the Ethics Committee of Chinese PLA General Hospital, with written informed consent from all patients. Tumor pathological diagnosis was confirmed by two independent pathology experts according to World Health Organization histological classification. Frozen samples were collected intraoperatively and immediately frozen to $-80^{\circ} \mathrm{C}$ in a refrigerator; the samples included five specimens each of grade I (PS), II (diffuse astrocytoma), III (anaplastic astrocytoma), and IV (GBM). The study was approved by the review board in accordance with ethical norms. All clinical investigations were conducted according to the principles expressed in the Declaration of Helsinki.

\section{iTRAQ sample preparation}

Fifty milligram sections from each of the 20 frozen tissue samples were selected for proteomics analysis. Each sample was rinsed with phosphate-buffered saline and then lyzed with lysis buffer (containing 2.5 M thiourea, $8 \mathrm{M}$ urea, $65 \mathrm{mM}$ dithiothreitol). Cell debris was removed by centrifugation at $14,000 \times g$ at $4{ }^{\circ} \mathrm{C}$ for 10 minutes. The protein concentration of each sample was measured by the Bradford method. ${ }^{14}$

Proteins from each sample were pooled together with the same total protein amount and digested with filter-aided sample preparation method. Digested peptides from the grade I, II, III, and IV samples were desalted in C18 columns (1cc, 30 mg, Oasis ${ }^{\circledR}$, Waters Company, Milford City, Massachusetts, USA). The desalted peptides were dried by vacuum centrifugation and stored at $-80^{\circ} \mathrm{C}$.

The pooled grade I, II, III, and IV samples were labeled with 114, 115, 118, and 121 8-plex iTRAQ reagents, respectively, according to the manufacturer's protocol (AB SCIEX Company, Farmingham City, Massachusetts, USA). After labeling, the labeled samples were mixed equally and dried by vacuum centrifugation. ${ }^{14}$

\section{Two dimensional LC-MS/MS}

The mixed labeled samples were first separated using a highperformance reverse phase liquid chromatography column 
(4.6×250 mm, C18, $3 \mu \mathrm{m}$, Waters Company, Milford City, Massachusetts, USA). The samples were loaded onto the column in buffer $\mathrm{A}(\mathrm{pH}=10,2 \%$ acetonitrile, $\mathrm{ACN})$, and gradient eluted by $5 \%-35 \%$ buffer $\mathrm{B}(90 \% \mathrm{ACN}, \mathrm{pH}=10$; flow rate, $0.6 \mathrm{~mL} / \mathrm{min}$ ) for 60 minutes. The eluted peptide were collected at one fraction per minute, and the 60 total fractions were pooled into 15 samples by combining fractions $1,16,31,46 ; 2,17,32,47$, and so on. A total of 15 fractions were analyzed by LC-MS/MS.

Each fraction was analyzed with a self-packed capillary reverse phase high-performance liquid chromatography column $(75 \mu \mathrm{m} \times 100 \mathrm{~mm}, \mathrm{C} 18,3 \mu \mathrm{m})$. The samples were loaded onto the column in buffer A ( $0.1 \%$ formic acid, $2 \% \mathrm{ACN})$, and gradient eluted by $5 \%-30 \%$ buffer $\mathrm{B}(0.1 \%$ formic acid, 99.9\% ACN; flow rate, $0.3 \mu \mathrm{L} / \mathrm{min}$ ) for 40 minutes. An LTQorbitrap Velos mass spectrometer (Thermo Fisher Scientific Corporation, Waltham City, Massachusetts, USA) was used to analyze the LC eluted peptides. Mass spectrometry data were obtained using the following parameters: ten datadependent MS/MS scans per full scan, full scans acquired at a resolution of 30,000 and MS/MS scans at a resolution of 7,500, charge state screening (including precursors with +2 to +4 charge state), dynamic exclusion (exclusion duration 60 seconds). ${ }^{14}$

\section{Data processing}

Mascot software (Matrix Science, London, UK; version 2.4.01) was used for database searching of all samples. In Mascot, the database was set to Swissprot human database and the digestion enzyme was set to trypsin. The parent mass tolerance was $10 \mathrm{ppm}$ and fragment ion was 0.5 Da. Carbamidomethyl of cysteine was set as a fixed modification, and a maximum of two miscleavage sites were allowed. For protein identification, Scaffold (version Scaffold_4.0.7, Proteome Software Inc., Portland, OR, USA) was used. Protein identification was set at false discovery rate (FDR) $<1 \%$ on both peptide and protein level and contained at least one unique peptide. Proteins containing similar peptides and could not be distinguished based on MS/MS analysis were grouped separately in order to meet the principle of simplicity. Scaffold Q+ (version Scaffold_4.3.2, Proteome Software Inc.) was used for iTRAQ quantification. Acquired intensities in the experiment were normalized globally at all runs. The reference channels were normalized to produce a 1:1 fold change. To normalize data, all normalizationcalculations used medians multiply methods. ${ }^{14}$

\section{Gene Ontology (GO) and IPA analysis}

For GO analysis, all differential proteins were analyzed in the Panther database (http://www.pantherdb.org/), and compared with the whole human genome. Proteins were classified based on molecular function, biological processes, and cellular component categories in $\mathrm{GO}$ annotations.

For IPA analysis, the differential proteins were analyzed in IPA software (Ingenuity Systems, Mountain View, CA, USA). The proteins were mapped to the IPA database and other databases in the disease and functional category, and the canonical pathways category, respectively, with Z-score and $P$-values rankings. ${ }^{14}$

\section{Western blotting analysis}

Five selected candidate biomarkers, including EGFR, matrix metalloproteinase-9 (MMP9), metalloproteinase inhibitor 1 (TIMP1), fibulin-2 and -5 , were validated by Western blot by the individual samples. All the primary antibodies against EGFR (Cat\# ab131498), MMP9 (Cat\# ab76003), TIMP1 (Cat\# ab61224), fibulin-2 (Cat\# ab125256), and fibulin-5 (Cat\# ab66339) were purchased from the Abcam (Cambridge, MA, USA). Quantificational analysis of Western blot data was done using Image J (National Institutes of Health, Bethesda City, Maryland, USA) and statically analyzed by one way analysis of variance in SPSS 18.0 (SPSS Inc., Chicago, IL, USA).

\section{RNA isolation and quantitative real-time polymerase chain reaction}

Total RNA samples were harvested following the methods described by Serra et al. ${ }^{15}$ The Taqman primers and probes for fibulin-2 and -5, and glyceraldehyde 3-phosphate dehydrogenase were obtained from validated and predesigned Gene Expression Assays (Life Technologies, Carlsbad, CA, USA). Total RNA extracting and real-time reverse transcriptase polymerase chain reaction experiments were performed following the methods described by Serra et al. ${ }^{15}$

\section{Cell proliferation assays}

MTT ((3-(4,5-dimethyl-2-thiazolyl)-2,5-diphenyl-2-H-tetrazolium bromide)) experiment was used to analyze anchor-independent growth of U251 cells. U251 cells were transfected with empty vectors or fibulin-2 and -5 expression vectors. Cell proliferation assays (MTT- experiment) was performed following the protocols described in references. ${ }^{16,17}$

\section{Anchorage-independent proliferation assay}

U251 cells were transfected with empty vectors or fibulin-2 and -5 expression vectors. The anchorage-independent proliferation was performed following the protocols described in references. ${ }^{18,19}$ 
Table I Number of upregulated proteins and downregulated proteins in different grades of astrocytomas analyzed by LC-MS/MS

\begin{tabular}{llll}
\hline $\begin{array}{l}\text { Clinical } \\
\text { classification }\end{array}$ & Upregulation & Downregulation & Total \\
\hline Grade II & 173 & 97 & 2,177 \\
Percentage & 7.95 & 4.46 & 100 \\
Grade III & 156 & 148 & 2,177 \\
Percentage & 7.17 & 6.80 & 100 \\
Grade IV & 325 & 137 & 2,177 \\
Percentage & 14.93 & 6.29 & 100 \\
\hline
\end{tabular}

Abbreviation: LC-MS/MS, liquid chromatography-tandem mass spectrometry.

\section{Transwell (in vitro invasion and migration) assay}

U251 cells were transfected with empty vectors or fibulin-2 and -5 expression vectors. The in vitro invasion or migration of cells was identified by transwell analysis. Transwell assays were performed following the methods provided in Zhao et al. ${ }^{20}$

\section{Results}

\section{Quantitative analysis of differential}

\section{proteome}

The tissue protein samples extracted from grade I, II, III, and IV astrocytomas were pooled respectively. The four pooled samples were iTRAQ-labeled and then analyzed by 2D LC-MS/MS. By querying the human Swissprot database with the Mascot algorithm, at 1\% FDR both in peptide and protein levels, 19,793 spectrums were matched from 130,959 spectrums. A total of 9,570 peptides were identified. A total of 2,190 proteins were identified from matched spectrums with $\geq 1$ peptides and 2,177 proteins were quantified by iTRAQ. By a ratio-fold change $>2$, compared to grade I astrocytomas, 173 (12.4\%), 304 (14\%), and 462 (21.2\%) proteins were differentially expressed in grade II, grade III, and grade IV astrocytomas, respectively (Tables 1 and $\underline{\mathrm{S} 1}$ ). By analyzing the distribution of the protein fold change (Figure 2), in all the three groups, the data set showed nearly symmetric distribution of fold change across the samples.

\section{PANTHER and IPA analysis}

To further study the biological function of the differential proteins between the different grades of astrocytoma, the differential proteins were analyzed by GO and IPA.

Next, to explore the possible function of differential proteins in grade II, III, and IV astrocytomas, the PANTHER classification system ${ }^{21}$ was used to search for the enrichment of the GO terms in differential proteins comparing to the whole human genome data. The cellular compartment, molecular function, and biological process of the differentially expressed proteins are presented in Figure 2. In the molecular function category (Figure 3A), the percentage of structural molecular activity were much higher, while the percentage of nucleic acid binding transcription factor were much lower in the differential proteins in grade II, III, and IV astrocytomas compared
A

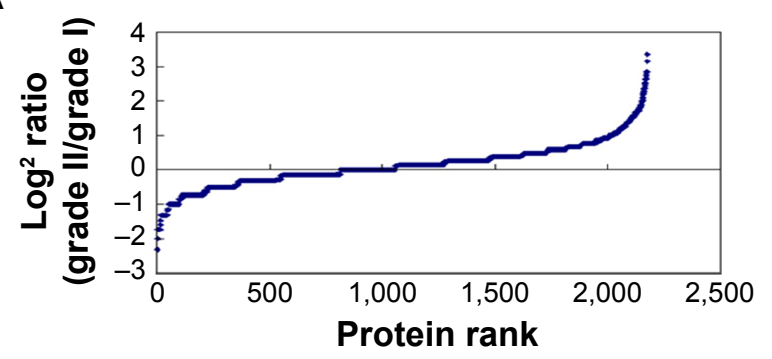

B

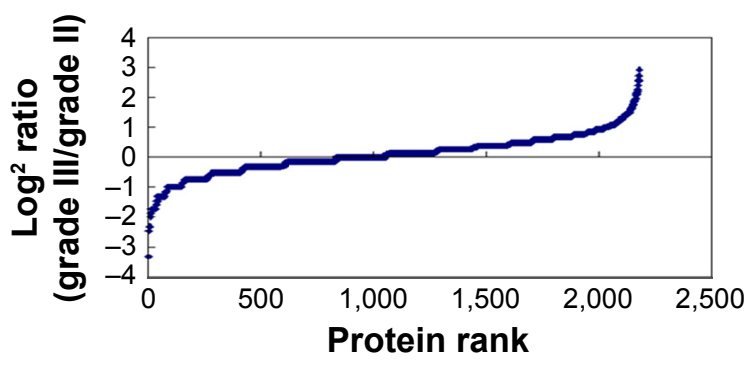

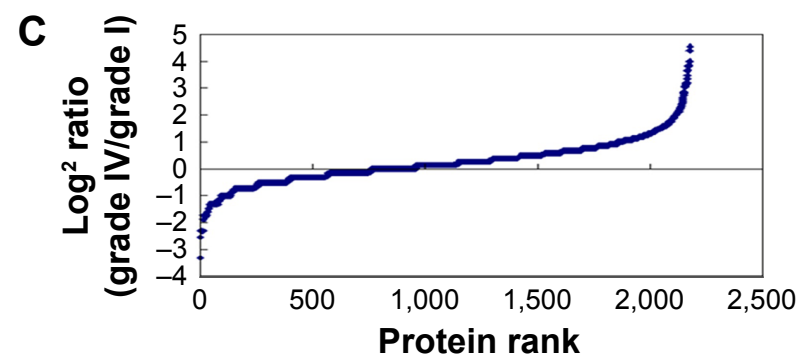

Figure 2 Distribution of proteins fold change in grade II (A), grade III (B), and grade IV (C) versus grade I astrocytoma. Note: Peptides and proteins were identified at I\% FDR both in peptide and protein levels.

Abbreviation: FDR, false discovery rate. 
A

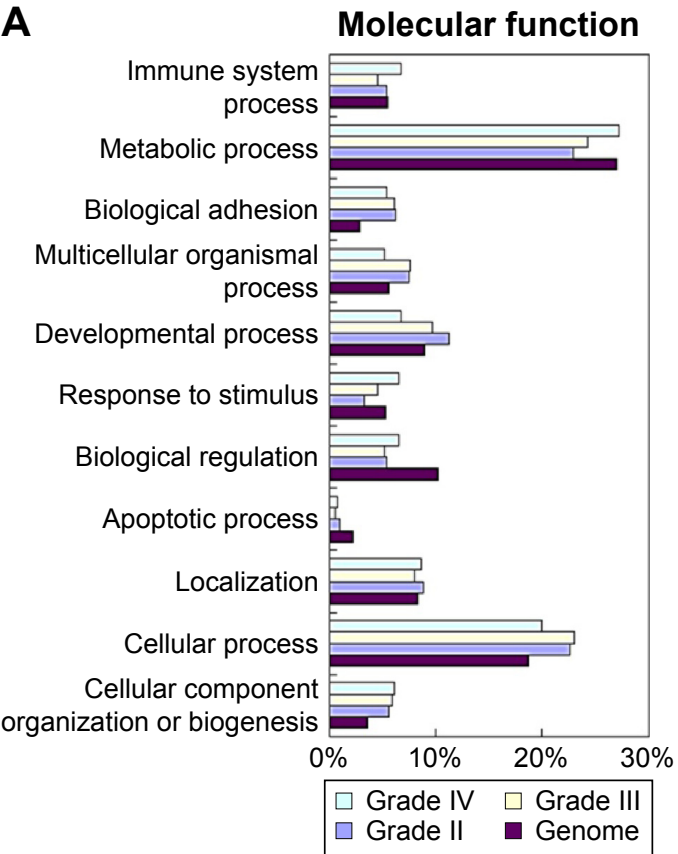

B

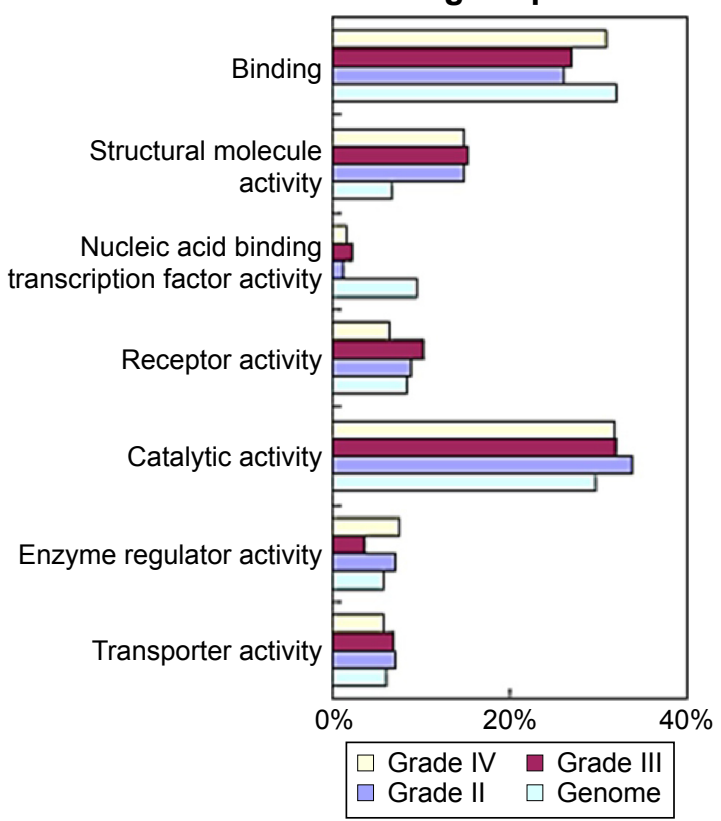

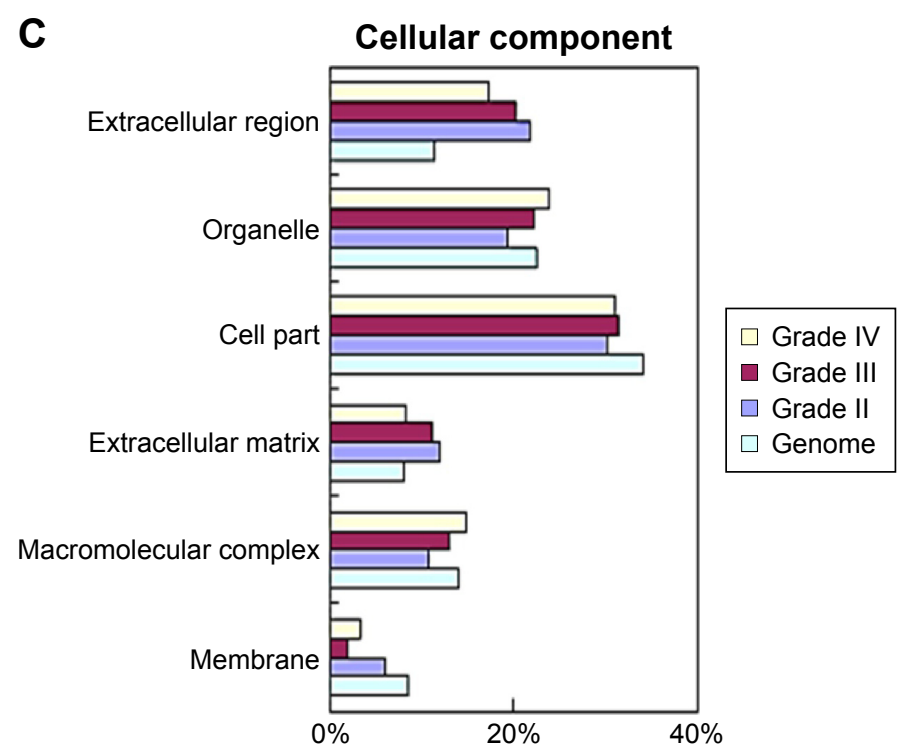

Figure $3 \mathrm{GO}$ analysis of differential proteins from low- to high-grade astrocytomas.

Notes: (A and B) Differential proteins in grade II, III, and IV astrocytomas were classified into molecular functions (A), biological process (B), and cellular component (C) categories for human genes, compared to the entire human genome by GO analysis. Categories with constitution of at least $2 \%$ were displayed in the bar charts. Abbreviation: GO, Gene Ontology.

with the whole genome data. In biological process category (Figure 3B), the biological adhesion function, cellular component organization, and biogenesis were overrepresented, whereas the biological regulation were underpresented. In the cellular component category (Figure 3C), extracellular region was overrepresented in all the three grades of astrocytoma, extracellular matrix (ECM) was overrepresented in grade II and III astrocytomas, whereas the membrane proteins were underrepresented, indicating that the ECM proteins play a role in the pathologic process of astrocytomas.
To further analyze the detailed difference between the different grades of astrocytoma, from low to high, IPA analysis was performed. In disease and function analysis, cell survival, cell viability, cell activation, cell proliferation, cell migration, cell invasion, cell movement and angiogenesis were increasingly activated from low- to high-grade of astrocytoma (Figure 4A). These results indicated that cell proliferation, cell invasion, and angiogenesis increase from low- to high-grade astrocytomas, and all these were consistent with previous laboratory investigations and clinical 
A

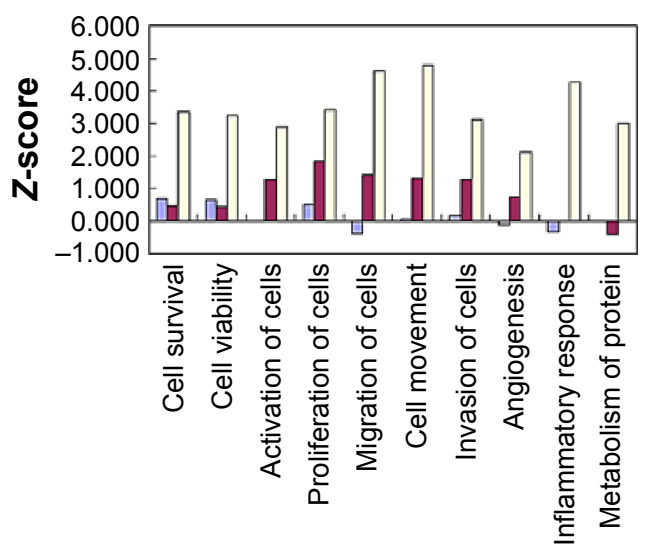

B

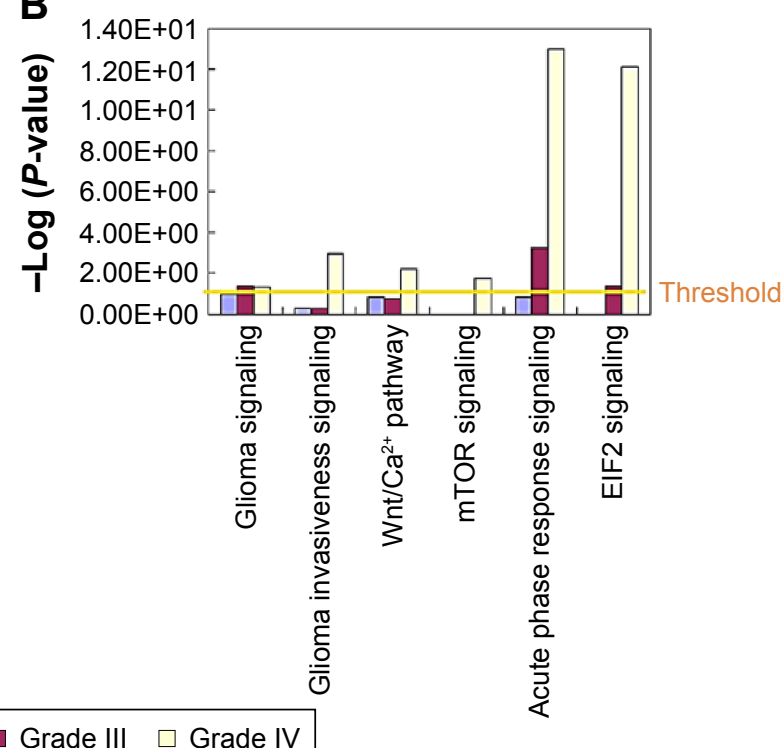

Figure 4 IPA analyses of differential proteins from low- to high-grade astrocytomas.

Notes: Disease and function analysis (A) and canonical pathways (B) in grade II, III, and IV astrocytomas. Z-score $>2$ : significantly activated; Z-score <-2, significantly inhibited. - Log $(P$-value $)>$ I.5: significantly enriched.

Abbreviations: elF2, eukaryotic initiation factor 2; IPA, ingenuity pathway analysis; mTOR, mechanistic target of rapamycin; Wnt, Wingless and int I.

observations of higher malignancy and worse prognosis from low- to high-grade astrocytomas. ${ }^{1-3,10}$ As a member of fibulin family, fibulin-5 was observed to be downregulated in all grade II/III/IV astrocytomas, and inhibit cell growth, cell invasion, and angiogenesis. ${ }^{22}$ The proteins participating in metabolism and molecular transporters were activated in GBM, indicating high tumor metabolic levels in GBM. Inflammatory response and accumulation of neutrophils were activated in GBM (Figure 4A), reflecting tumor-induced inflammatory reaction in GBM.

To further detect the detailed molecular mechanism of tumor development in low- and high-grade astrocytomas, pathway analysis was performed. Pathway analysis showed that the pathway of glioma signaling were enriched in grades III and IV, and glioma invasive signaling, $\mathrm{Wnt} / \mathrm{Ca}^{2+}$ pathway, mTOR pathway were enriched in GBM, which were consistent with the previous study, ${ }^{3,7,8}$ indicating that our proteomic data indeed reflected the pathological process of glioma (Figure 4B). In the glioma signaling pathway, EGFR were activated in grade II/III/IV astrocytomas, which were consistent with the previous studies showing amplification/ overexpression of EGFR in GBM. ${ }^{7,23}$ The data suggested that the EGFR/ERK/MEK pathway were increasingly activated from low- to high-grade astrocytomas, which activated cell growth and cell proliferation. In GBM, levels of several important ECM and extracellular proteins belonging to the invasion-related signaling pathways, such as MMP9, plasminogen, vitronectin, increased significantly but there were no such obvious changes in low-grade astrocytomas, indicating that in the high-grade astrocytomas, glioma invasiveness signaling was significantly activated, which led to activation of cell invasion and further metastasis (see our graphical abstract shown in Figure 1). On the contrary, a metalloproteinase inhibitor, TIMP3, was downregulated in both GBM and low-grade astrocytomas. Surprisingly, another metalloproteinase inhibitor, TIMP1 was remarkably increased in GBM. We also observed that the eukaryotic initiation factor 2 pathway and acute phase response signaling were dramatically enriched in GBM, indicating that exuberant protein synthesis and serious tumor-induced inflammatory reaction occur in the high-grade astrocytomas (Figure 4B).

Table 2 Quantitative value of candidate biomarkers by iTRAQ and Western blot quantitation methods

\begin{tabular}{llll}
\hline $\begin{array}{l}\text { Protein } \\
\text { name }\end{array}$ & $\begin{array}{l}\text { Accession } \\
\text { number }\end{array}$ & $\begin{array}{l}\text { iTRAQ } \\
\text { quantification }\end{array}$ & Western blot \\
\hline EGFR & E9PFD7 & I:3.7:2.2:2.5 & I:I.64:I.86:I.89 \\
TIMPI & P0I033 & I:I.I:I.I:2.3 & I:I.09:I.32:I.80 \\
MMP9 & PI4780 & I:I.5:I.5:8.3 & I:I.80:I.5I:2.00 \\
FBLN5 & G3V4U0 & I:0.5:0.4:0.6 & I:0.76:0.53:0.36 \\
FBLN2 & F5HIF3 & I:0.4:0.I:0.2 & I:0.40:0.23:0.14 \\
\hline
\end{tabular}

Abbreviations: EGFR, epidermal growth factor receptor (OS=Homo sapiens $G N=$ EGFR; $P E=3$ SV =2); FBLN2, fibulin-2 (OS = Homo sapiens GN = FBLN2 PE =4 $\mathrm{SV}=1$ ); FBLN5, fibulin-5 (OS = Homo sapiens GN = FBLN5 PE =4 SV =1); iTRAQ, isobaric tags for relative and absolute quantitation; MMP9, matrix metalloproteinase-9 ( $\mathrm{OS}=$ Homo sapiens $\mathrm{GN}=$ MMP9 PE =I SV =3); TIMPI, metalloproteinase inhibitor I (OS = Homo sapiens GN = TIMPI PE =I SV =I). 


\section{Western blot validations}

Through biofunction and pathway analysis, five differential expressing proteins, for example, EGFR, TIMP1, MMP9, fibulin-2 and -5 were selected for Western blot validation. As shown in Table 2, results from iTRAQ and Western blot had a similar trend. EGFR, a previous reported biomarker, was upregulated in grade II/III/IV astrocytomas, which proves our experimental results were credible. Four newly reported candidate biomarkers, MMP9 and TIMP, were upregulated in the GBM group, whereas fibulin-2 and -5 were statistically downregulated in grade II/III/IV astrocytomas, and the decrease of these proteins was significantly correlated with advanced clinical stage (Figure 5).

A
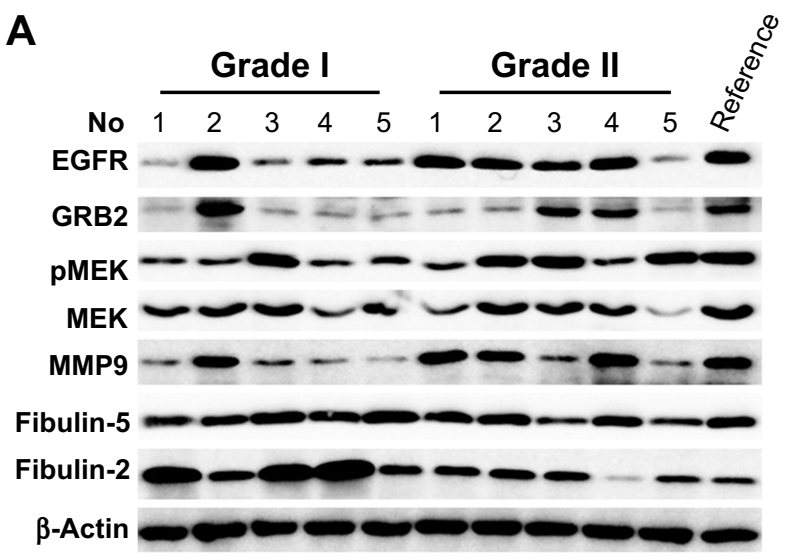

C
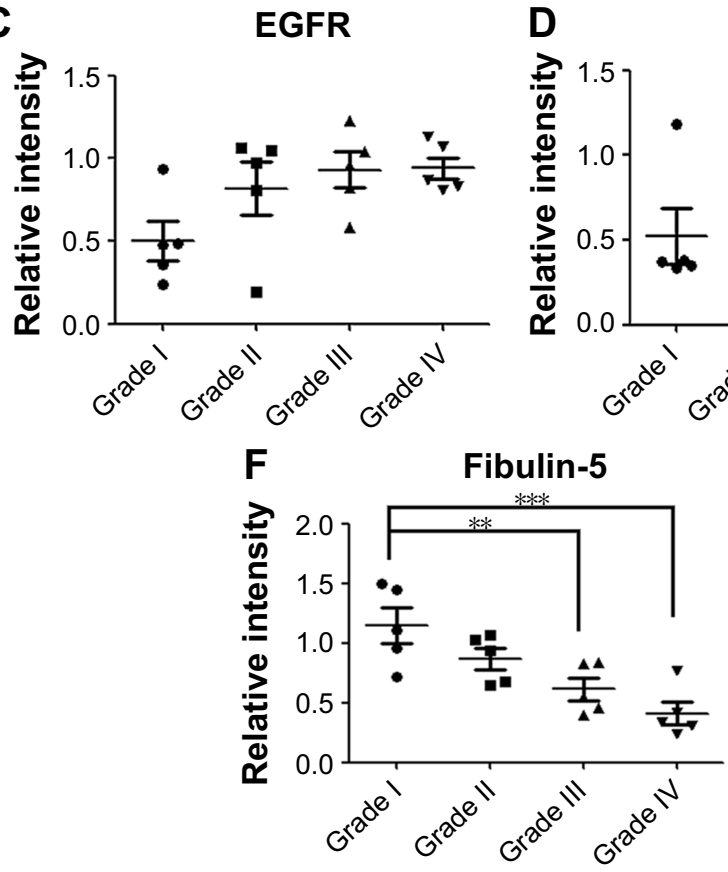

Overexpression of fibulin- 2 and -5 inhibit in vitro growth, migration, or invasion of glioma cells

It is necessary to identify whether mRNA level of fibulins is downregulated in grade II/III/IV astrocytomas. The results showed that the mRNA level of fibulin- 2 and -5 was statistically downregulated in grade II/III/IV astrocytomas, and low level of mRNA was significantly correlated with advanced clinical stage (Figure 6).

To identify the potential roles of fibulin- 2 and -5 in glioma, U251 cells were transfected with pCMV-fibulin-5 or pCMV-fibulin-2 vectors, with empty vector as control. Overexpression of both fibulin-2 and -5 reduced the proliferation

\section{B}
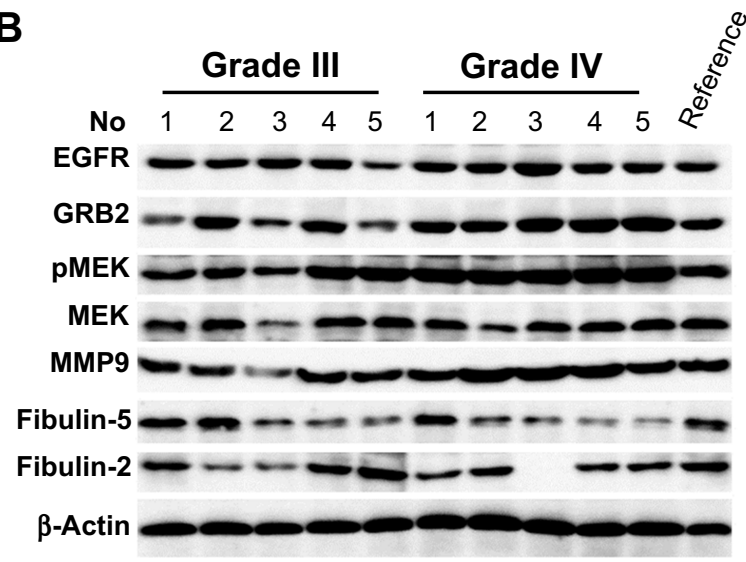

TIMP1

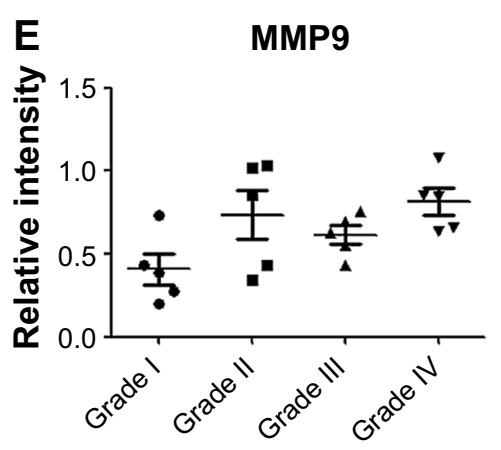

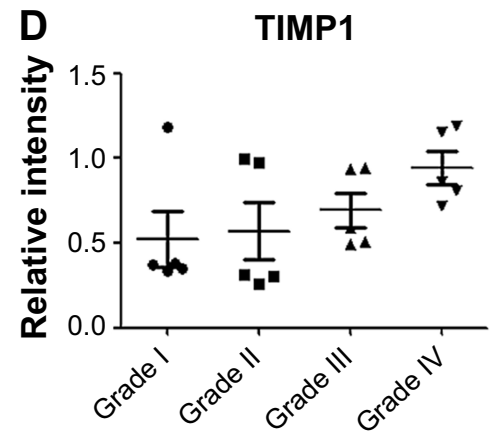

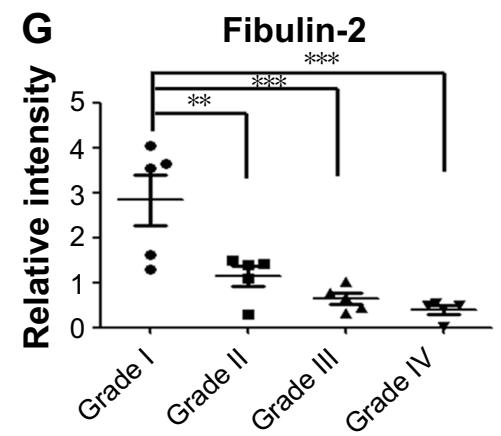

Figure $\mathbf{5}$ Western blot validations for five differential proteins.

Notes: (A and B) The results are shown as representative Western blot photograph of the five candidate biomarkers in different grades of astrocytoma. Scatter plot of EGFR (C), TIMPI (D), TIMPI (E), fibulin-5 (F), and fibulin-2 (G) are shown. $* * P<0.0$ I, $* * * P<0.01$. The $P$-value was obtained from LSD with one-way ANOVA analysis. Data are mean \pm SEM.

Abbreviations: EGFR, epidermal growth factor receptor; GRB2, growth factor receptor-bound protein 2; MMP9, matrix metalloproteinase-9; TIMP, tissue inhibitor of metalloproteinase; MEK, Mitogen-activated protein kinase kinase; $\mathrm{P}-\mathrm{MEK}$, phosphorylated MEK. 
A

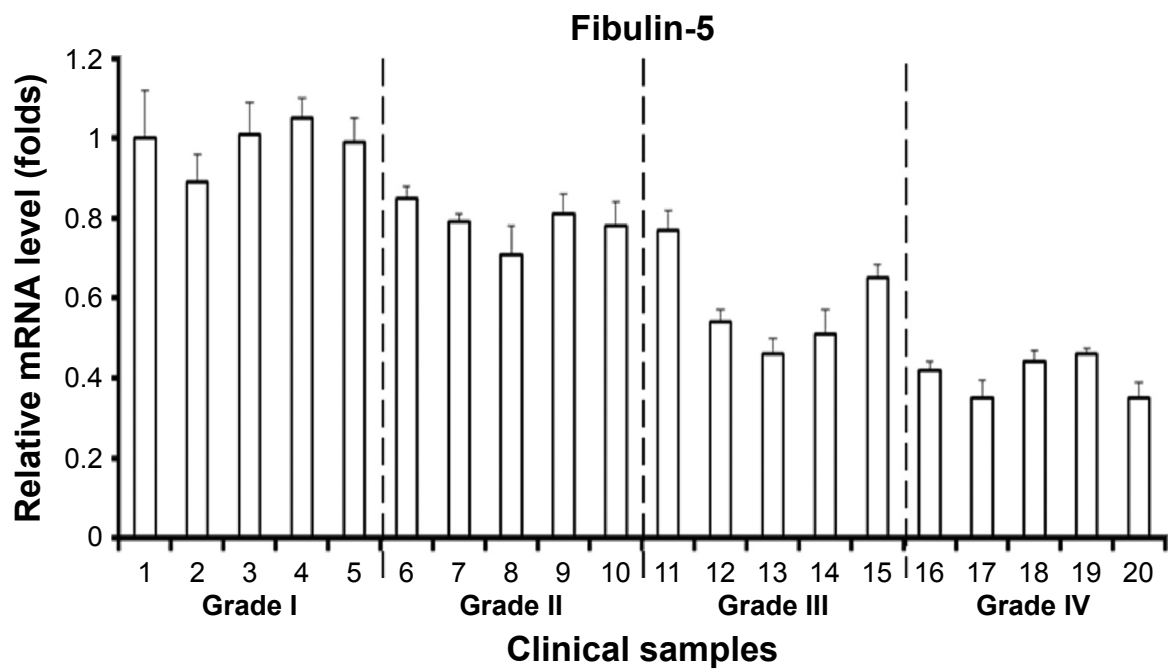

B

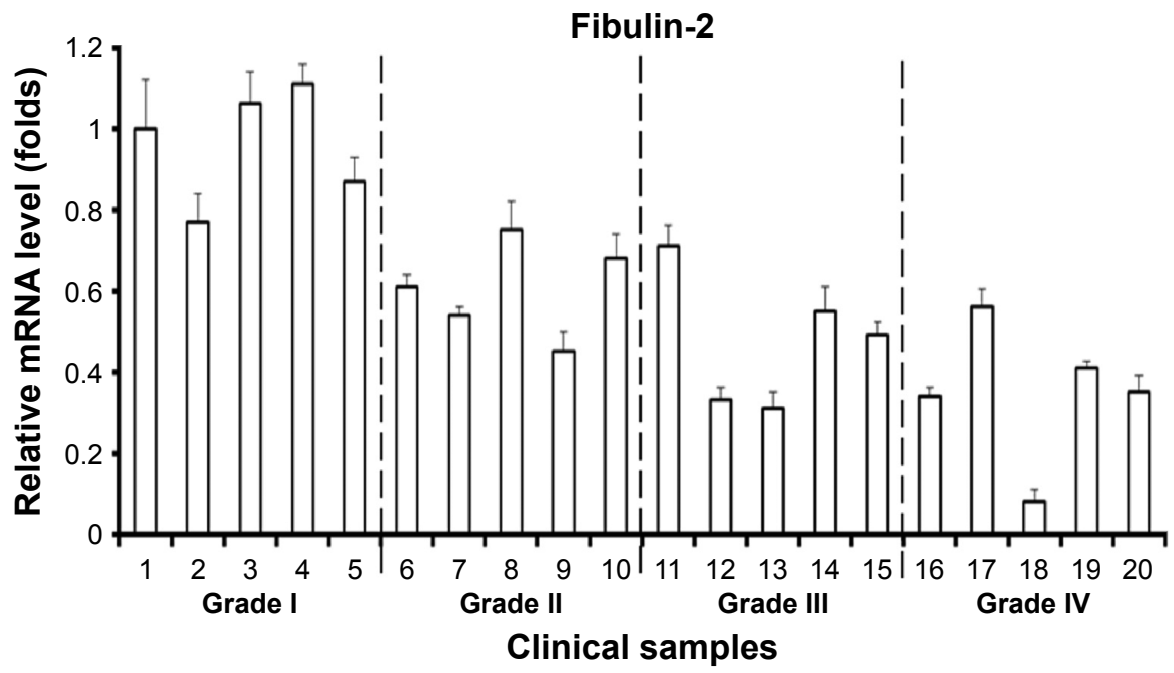

Figure 6 The mRNA level of fibulin-2 and fibulin-5 in clinical specimens.

Note: The endogenous mRNA level of fibulin-5 (A) and fibulin-2 (B) was shown. Data are mean \pm SD.

Abbreviation: mRNA, messenger RNA.

ability of U251 cells ( $P<0.05$, respectively; Figure 7A and $B$ ). The expression of fibulin- 2 or -5 was significantly enhanced after transfection of fibulin-2 and -5 expression vectors (Figure 7C and D).

Next, in vitro anchorage-independent growth, invasion, and migration of U251 cells were tested. Overexpression of fibulin-2 and -5 decreased colony formation, migration, and invasion of U251 cells $(P<0.05$, respectively; Figures 8 and 9). Taken together, both fibulin-2 and -5 might have an anticancer effect in glioma.

\section{Discussion}

Astrocytoma is a heterogeneous neoplasms originating from astrocytes. There were significant differences in prognosis and therapeutic decisions between low- and high-grade astrocytomas. However, given the extensive heterogeneity of astrocytic tumors, accurate differentiation between malignant high- and low-grade astrocytoma is difficult on the basis of their microscopic appearance. To identify the more accurate biomarkers between low- and high-grade astrocytomas, we preformed proteomics profiling of these glioma subtypes to discover differentially expressed protein biomarkers. We performed a proteomic analysis of these subtypes of gliomas and found differential expression of protein biomarkers.

By differential proteomics study, we found that some ECM proteins were upregulated or downregulated in different grades of astrocytomas, including MMPs, TIMPs, and fibulins. ${ }^{24}$ The breakdown or degradation of extra-cellular matrix mediated by MMPs, especially MMp-2 or MMp-9, would participate in tumor progress via promoting cancer cells invasion or migration. ${ }^{25-28}$ In this article, we identified 


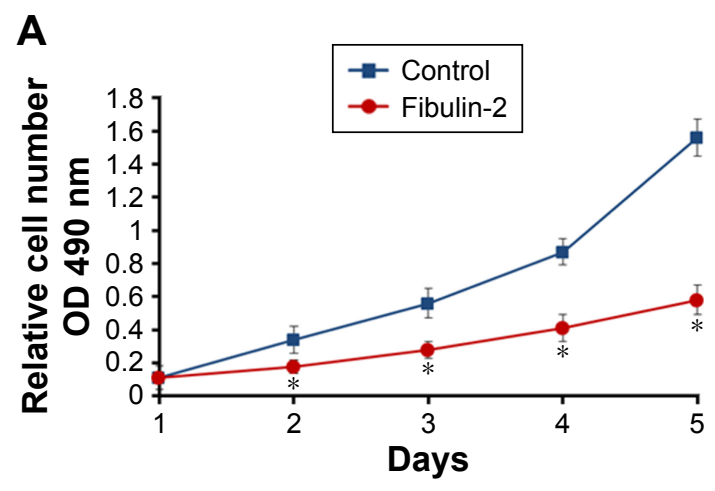

C

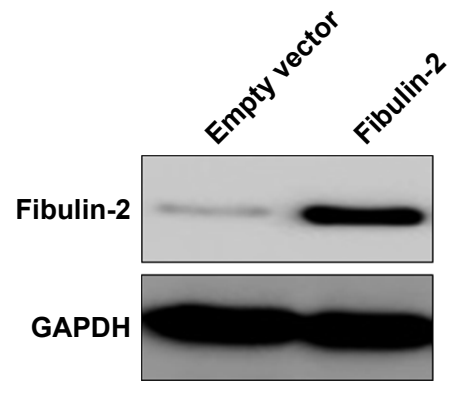

B

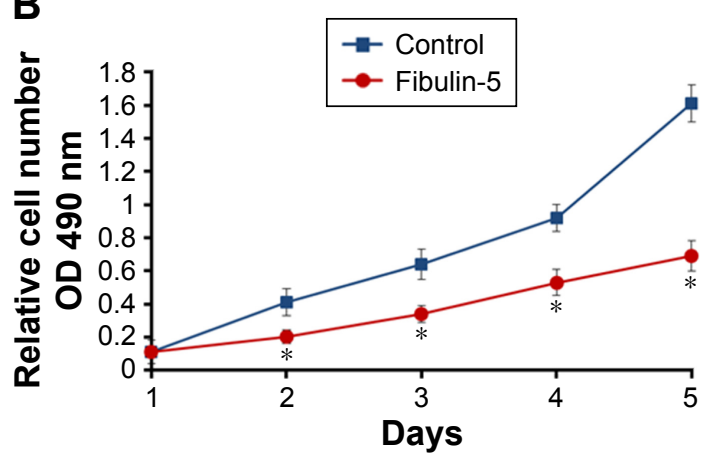

D

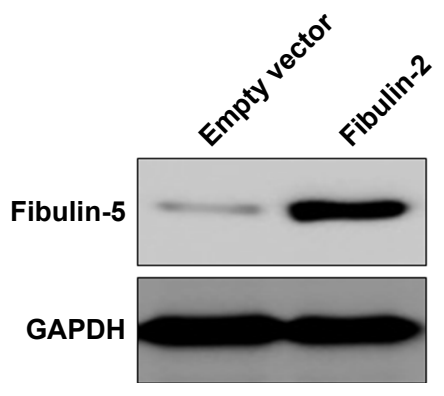

Figure 7 Fibulin-5 (A) and fibulin-2 (B) decrease glioma cells proliferation in vitro.

Notes: U25I cells were transfected with the respective plasmids. Then, relative cell numbers were determined by the MTT assay. Relative cell numbers (A and B) shown are mean \pm SD of triplicate measurements and have been repeated three times with similar OD value results. The expression (C and $\mathbf{D})$ of Fibulin-2 (C) or Fibulin-5 (D) was examined by Western blot assays. $* P<0.05(\mathrm{~N}=3)$. $* P<0.05$ from Bonferroni correction with or without two-way ANOVA.

Abbreviations: GAPDH, glyceraldehyde 3-phosphate dehydrogenase; SD, standard deviation; OD, optical density; MTT, 3-(4,5-dimethyl-2-thiazolyl)-2,5-diphenyl-2-Htetrazolium bromide.

and validated the upregulation of MMP9 in GBM and the downregulation of TIMP3 in both low- and high-grade astrocytomas, which could promote the breakdown of ECM, and then promote tumor invasion in GBM. This result was consistent with previous studies. ${ }^{29-32}$ However, as another inhibitor of the zinc-dependent endopeptidase, TIMP1 was significantly upregulated in GBM by the observation of both proteomic data and individual Western blot validation. Traditionally, tissue inhibitors of MMPs have played a protective role in the invasion and metastasis of tumor. The possibility of the upregulation of TIMP1 in GBM is caused by some kind of feedback mechanism to antagonize the increase of MMPs in GBM. Other than metalloproteinase inhibition function, Nalluri et $\mathrm{al}^{33}$ and Rojiani et $\mathrm{al}^{34}$ provided evidence that the elevated TIMP messenger RNA levels are also associated with poor clinical outcome in patients with aggressive malignant lung adenocarcinoma. Functional analysis showed that overexpressed TIMP-1 promotes tumor development through alterations in angiogenesis, increased tumorigenicity, and invasive behavior. Therefore, we speculated another possibility that the upregulation of TIMP-1 might play a role in the angiogenesis and invasion of GBM in a MMP-independent way.

Fibulins are composed of a globular fibulin-type module in C-terminal and calcium-binding epidermal growth factor-like modules. ${ }^{35}$ In mammalian cells, the fibulin protein family consists of seven members, fibulins 1-7. Fibulins stabilize the structure and integrity of ECM. ${ }^{36-38}$ In addition, fibulins are also involved in tumorigenesis or vasculogenesis. ${ }^{22,37}$ Among seven fibulins, fibulin-5 has recently been identified as a potential tumor suppressor in human cancers. Several studies showed that fibulin-5 expression is downregulated in many types of tumors and fibulin-5 may be a negative regulator of growth and metastasis of human cancers, for example, bladder cancer, prostate carcinoma, renal cancer, or hepatocellular carcinoma. ${ }^{39-42}$ Yi et al, ${ }^{43}$ Law et al, ${ }^{44}$ and Alcendor et $\mathrm{al}^{45}$ showed that low level of fibulin-5 associated with a shorter overall survival in patients with glioma. Moreover, no previous study reported the relationship between fibulin-2 and astrocytoma. ${ }^{46}$ Albig et $\mathrm{al}^{47}$ reported that fibulin-3 is downregulated in peripheral tumors and is considered to inhibit tumor growth. However, $\mathrm{Hu}$ et al found that fibulin-3 were highly expressed in glioma and cultured glioma cells compared with normal brain tissues or cultured astrocytes and would results in increasing growth of glioma cells. ${ }^{48-50}$

In this study, we identified three fibulin proteins, fibulin-1, -2, and -5 , in astrocytomas. Fibulin-1 was slightly upregulated in high-grade astrocytomas. This result was 
A

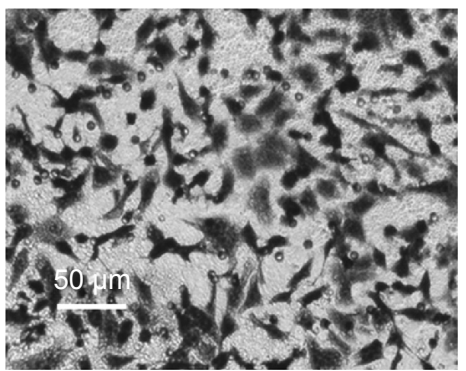

D

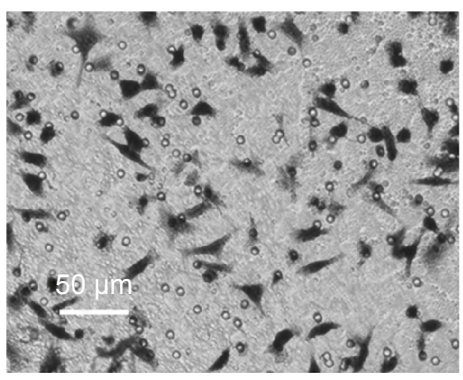

G

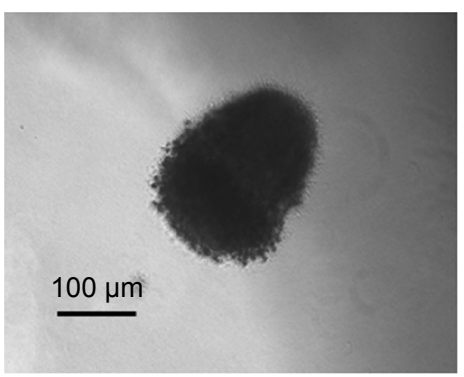

B

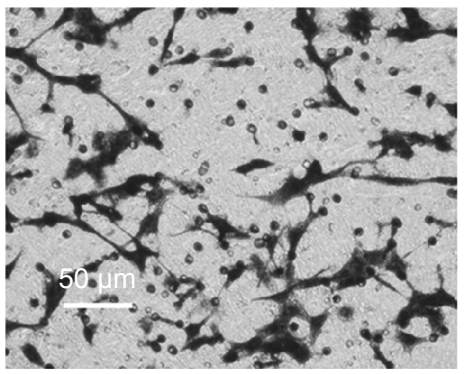

E

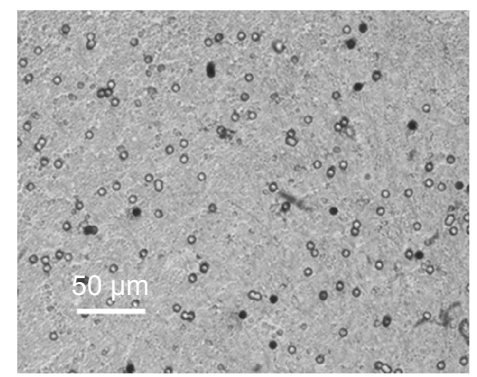

H

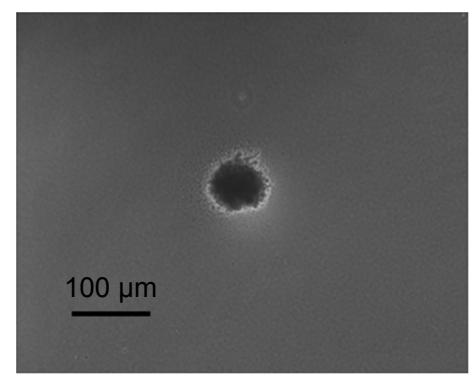

C

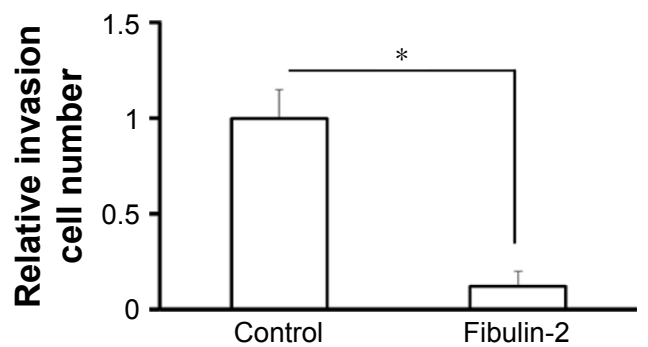

$\mathbf{F}$

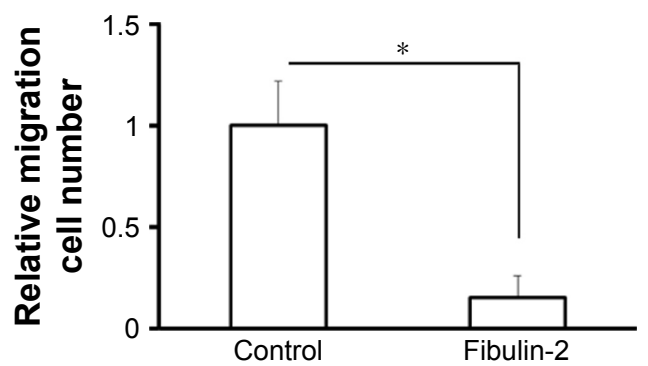

I

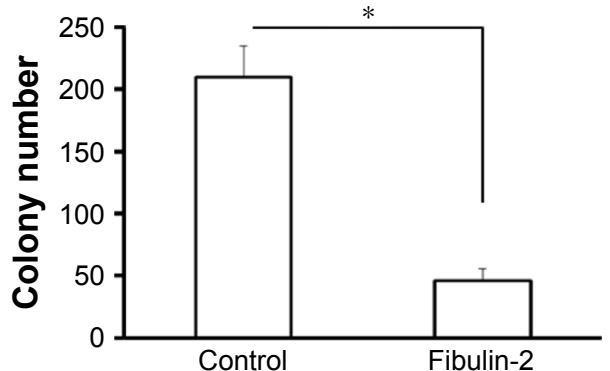

Figure 8 Fibulin-2 overexpression inhibits cell migration $(\mathbf{A}-\mathbf{C})$, cell invasion (D-F), and anchorage-independent growth (G-I) in glioma cells. Note: $* P<0.05(\mathrm{~N}=3)$.

similar to IHC data. ${ }^{51}$ Both fibulin-2 and -5 were downregulated in grade II/III/IV astrocytomas compared with grade I astrocytoma. To confirm the effect of fibulin-2 and -5 , U251 cells, a typical glioma cell line, were transfected with the expression vectors of fibulin-2 and -5 . Overexpression of fibulin- 2 and -5 reduced in vitro proliferation, migration, and invasion by cells. Thus we suggested that fibulin-2 and -5 function as tumor suppressors in glioma. On the contrary, fibulin-3 was highly expressed in glioma, and promotes the movement and invasion of tumor cells and angiogenesis. Although the function was unknown, fibulin-1 was also upregulated in glioma. The fibulin family has a potential role as a diagnostic biomarker and therapeutic target of astrocytoma, and its molecular mechanism needs further study.
Previous studies have identified several candidate biomarkers in different stage of astrocytomas, such as upregulation of calcylin, tubulin-specific chaperone A in grade IV glioma, overexpression of phosphoprotein enriched in astrocytes 15 in grade II and III gliomas, which were consistent with our proteomic study. ${ }^{52-54}$ The integration of multiomics data analysis by different laboratories would provide more comprehensive information to differentiate and discriminate between different kinds of glioma.

\section{Conclusion}

In summary, this study compared the differential tumor tissue proteome among grade I, II, III, and IV astrocytomas. By bioinformatics analysis, cell proliferation, cell invasion, and angiogenesis increased from low- to high-grade 

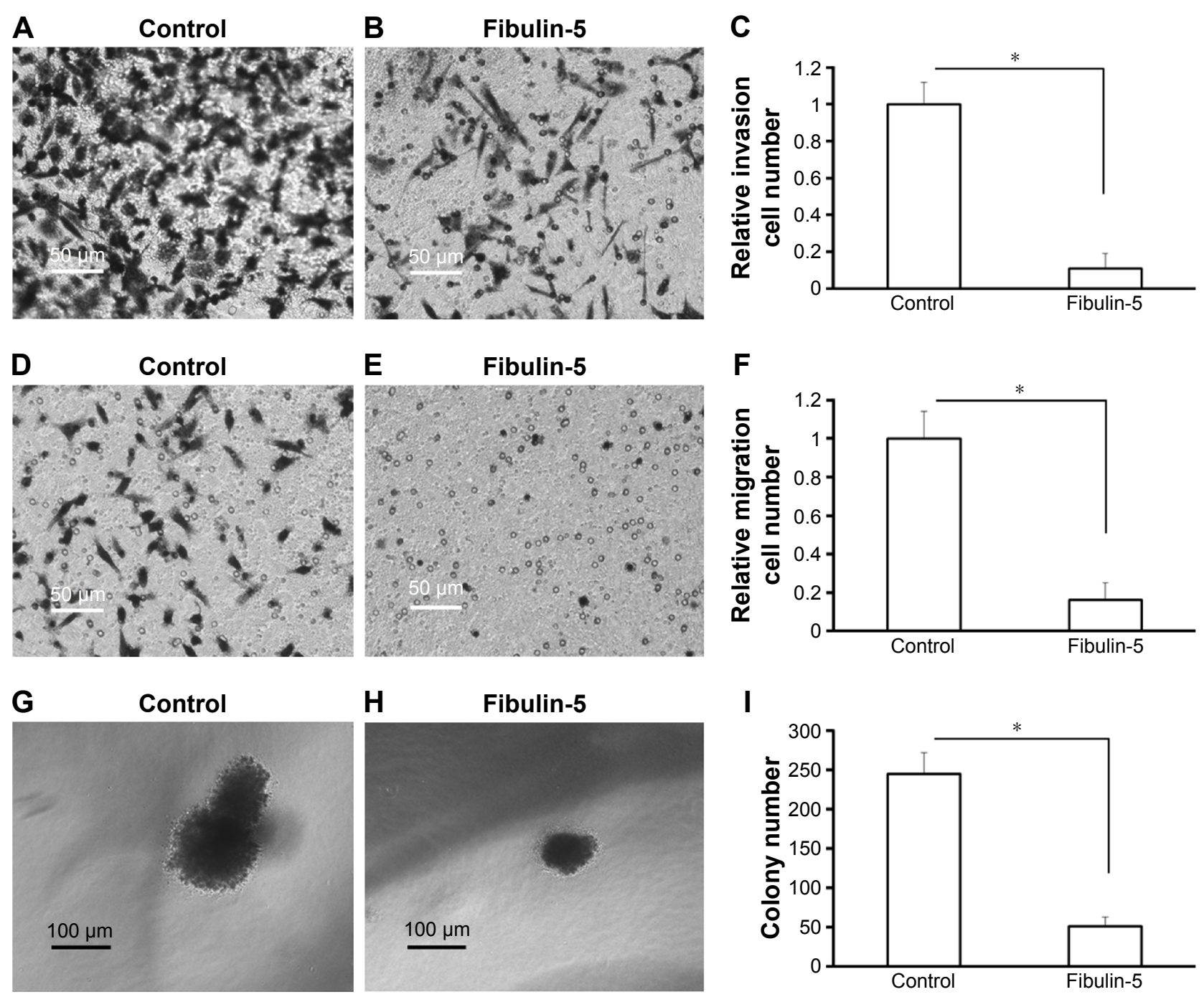

Figure 9 Fibulin-5 overexpression inhibits cell migration (A-C), cell invasion (D-F) and anchorage-independent growth (G-I) in glioma cells. Note: $* P<0.05(\mathrm{~N}=3)$.

astrocytomas. The ECM-related proteins play roles in the pathologic process of astrocytoma. Five identified differential expressing proteins, for example, EGFR, MMP9, TIMP, fibulin- 2 and -5 were validated by Western blot. Functional analysis showed that both fibulin-2 and -5 may perform an anticancer effect by inhibiting in vitro cell proliferation, cell migration, and cell invasion in glioma cells. The novel molecular biomarkers are likely to be used for accurate classification of astrocytoma and likely to be the target for drug development.

\section{Acknowledgments}

This work is supported by a State Key Laboratory Program Funding (No SKLMN 2014001) from State Key Laboratory of Medical Neurobiology, Fudan University. We thank
Dr Zhengguang Guo from the Chinese Academy of Medical Sciences and Peking Union Medical College (Beijing, People's Republic of China) and Prof Liang in General Hospital of Shenyang Military Area Command (Shenyang, People's Republic of China) for the help and advice.

\section{Author contributions}

All authors made substantial contributions to the design and conception; acquisition, analysis or interpretation of data. Authors took part in either drafting or revising the manuscript. TR, SL, and AS carried out experiments and drafted the manuscript. ZW participated in experiments. AS designed the study. At the same time, authors gave final approval of the version to be published; and agree to be accountable for all aspects of the work in ensuring that 
questions related to the accuracy or integrity of any part of the work are appropriately investigated and resolved.

\section{Disclosure}

The authors report no conflicts of interest in this work.

\section{References}

1. DeAngelis LM. Brain tumors. N Engl J Med. 2001;344(2):114-123.

2. Maher EA, Furnari FB, Bachoo RM, et al. Malignant glioma: genetics and biology of a grave matter. Genes Dev. 2001;15(11):1311-1333.

3. Jayaram S, Gupta MK, Polisetty RV, Cho WC, Sirdeshmukh R. Towards developing biomarkers for glioblastoma multiforme: a proteomics view. Expert Rev Proteomics. 2014;11(5):621-639.

4. Westermark B. Glioblastoma - a moving target. Ups J Med Sci. 2012; 117(2):251-256

5. Merlo A. Genes and pathways driving glioblastomas in humans and murine disease models. Neurosurg Rev. 2003;26(3):145-158.

6. Soni D, King JA, Kaye AH, Hovens CM. Genetics of glioblastoma multiforme: mitogenic signaling and cell cycle pathways converge. J Clin Neurosci. 2005;12(1):1-5.

7. Cancer Genome Atlas Research Network. Comprehensive genomic characterization defines human glioblastoma genes and core pathways. Nature. 2008;455(7216):1061-1068.

8. Rao RD, James CD. Altered molecular pathways in gliomas: an overview of clinically relevant issues. Semin Oncol. 2004;31(5):595-604.

9. He J, Liu Y, Zhu T, et al. CD90 is identified as a candidate marker for cancer stem cells in primary high-grade gliomas using tissue microarrays. Mol Cell Proteomics. 2012;11(6):M111.010744.

10. Gimenez M, Souza VC, Izumi C, et al. Proteomic analysis of lowto high-grade astrocytomas reveals an alteration of the expression level of raf kinase inhibitor protein and nucleophosmin. Proteomics. 2010;10(15):2812-2821.

11. Polisetty RV, Gautam P, Gupta MK, et al. Heterogeneous nuclear ribonucleoproteins and their interactors are a major class of deregulated proteins in anaplastic astrocytoma: a grade III malignant glioma. J Proteome Res. 2013;12(7):3128-3138.

12. Odreman F, Vindigni M, Gonzales ML, et al. Proteomic studies on lowand high-grade human brain astrocytomas. J Proteome Res. 2005;4(3): 698-708.

13. Sallinen SL, Sallinen PK, Haapasalo HK, et al. Identification of differentially expressed genes in human gliomas by DNA microarray and tissue chip techniques. Cancer Res. 2000;60(23):6617-6622.

14. Guo Z, Liu X, Li M, et al. Differential urinary glycoproteome analysis of type 2 diabetic nephropathy using 2D-LC-MS/MS and iTRAQ quantification. $J$ Transl Med. 2015;13:371.

15. Serra N, Rosales R, Masana L, Vallvé JC. Simvastatin increases fibulin-2 expression in human coronary artery smooth muscle cells via RhoA/Rho-kinase signaling pathway inhibition. PLoS One. 2015; 10(7):e0133875.

16. Qin H, Sha J, Jiang C, et al. miR-122 inhibits metastasis and epithelialmesenchymal transition of non-small-cell lung cancer cells. OncoTargets Ther. 2015;8:3175-3184.

17. Zhu M, Li M, Zhang F, et al. FBI-1 enhances ETS-1 signaling activity and promotes proliferation of human colorectal carcinoma cells. PLoS One. 2014;9(5):e98041.

18. Cao P, Feng F, Dong GF, et al. Estrogen receptor $\alpha$ enhances the transcriptional activity of ETS-1 and promotes the proliferation, migration and invasion of neuroblastoma cell in a ligand dependent manner. BMC Cancer. 2015;15:491.

19. Jia H, Yang Q, Wang T, et al. Rhamnetin induces sensitization of hepatocellular carcinoma cells to a small molecular kinase inhibitor or chemotherapeutic agents. Biochim Biophys Acta. 2016;1860(7): $1417-1430$.
20. Zhao J, Bai Z, Feng F, et al. Cross-talk between EPAS-1/HIF-2 $\alpha$ and PXR signaling pathway regulates multi-drug resistance of stomach cancer cell. Int J Biochem Cell Biol. 2016;72:73-88.

21. Mi H, Lazareva-Ulitsky B, Loo R, et al. The PANTHER database of protein families, subfamilies, functions and pathways. Nucleic Acids Res. 2005;33(Database issue):D284-D288.

22. Sheng XD, Chen H, Wang H, et al. Fibulin-5 is a prognostic marker that contributes to proliferation and invasion of human glioma cells. Asian Pac J Cancer Prev. 2015;16(2):769-773.

23. Sangar V, Funk CC, Kusebauch U, Campbell DS, Moritz RL, Price ND. Quantitative proteomic analysis reveals effects of epidermal growth factor receptor (EGFR) on invasion-promoting proteins secreted by glioblastoma cells. Mol Cell Proteomics. 2014;13(10): 2618-2631.

24. Kumar A, El-Osta A, Hussain AA, Marshall J. Increased sequestration of matrix metalloproteinases in ageing human Bruch's membrane: implications for ECM turnover. Invest Ophthalmol Vis Sci. 2010; 51(5):2664-2670.

25. Yang Q, Feng F, Zhang F, et al. LINE-1 ORF-1p functions as a novel HGF/ETS-1 signaling pathway co-activator and promotes the growth of MDA-MB-231 cell. Cell Signal. 2013;25(12):2652-2660.

26. Gialeli C, Theocharis AD, Karamanos NK. Roles of matrix metalloproteinases in cancer progression and their pharmacological targeting. FEBS J. 2011;278(1):16-27.

27. Weng CJ, Chau CF, Hsieh YS, Yang SF, Yen GC. Lucidenic acid inhibits PMA-induced invasion of human hepatoma cells through inactivating MAPK/ERK signal transduction pathway and reducing binding activities of NF-kappaB and AP-1. Carcinogenesis. 2008;29(1): 147-156.

28. Murphy G. Tissue inhibitors of metalloproteinases. Genome Biol. 2011;12(11):233.

29. Tabouret E, Boudouresque F, Farina P, et al. MMP2 and MMP9 as candidate biomarkers to monitor bevacizumab therapy in high-grade glioma. Neuro Oncol. 2015;17(8):1174-1176.

30. Ma D, Jia H, Qin M, et al. MiR-122 induces radiosensitization in non-small cell lung cancer cell line. Int J Mol Sci. 2015;16(9):22137-22150.

31. Chen Y, Feng F, Gao XD, et al. MiRNA153 reduces effects of chemotherapeutic agents or small molecular kinase inhibitor in HCC cells. Curr Cancer Drug Targets. 2015;15(3):176-187.

32. Zerrouqi A, Pyrzynska B, Febbraio M, Brat DJ, Van Meir EG. P14ARF inhibits human glioblastoma-induced angiogenesis by upregulating the expression of TIMP3. J Clin Invest. 2012;122(4):1283-1295.

33. Nalluri S, Ghoshal-Gupta S, Kutiyanawalla A, et al. TIMP-1 inhibits apoptosis in lung adenocarcinoma cells via interaction with Bcl-2. PLoS One. 2015;10(9):e0137673.

34. Rojiani MV, Ghoshal-Gupta S, Kutiyanawalla A, Mathur S, Rojiani AM. TIMP-1 overexpression in lung carcinoma enhances tumor kinetics and angiogenesis in brain metastasis. J Neuropathol Exp Neurol. 2015; 74(4):293-304.

35. Hwang CF, Shiu LY, Su LJ, et al. Oncogenic fibulin-5 promotes nasopharyngeal carcinoma cell metastasis through the FLJ10540/ AKT pathway and correlates with poor prognosis. PLoS One. 2013; 8(12):e84218.

36. Nakamura T, Lozano PR, Ikeda $Y$, et al. Fibulin-5/DANCE is essential for elastogenesis in vivo. Nature. 2002;415(6868):171-175.

37. Schiemann WP, Blobe GC, Kalume DE, Pandey A, Lodish HF. Contextspecific effects of fibulin-5 (DANCE/EVEC) on cell proliferation, motility, and invasion. Fibulin-5 is induced by transforming growth factor-beta and affects protein kinase cascades. J Biol Chem. 2002; 277(30):27367-27377.

38. Papke CL, Yanagisawa H. Fibulin-4 and fibulin-5 in elastogenesis and beyond: Insights from mouse and human studies. Matrix Biol. 2014;37: 142-149.

39. Wlazlinski A, Engers R, Hoffmann MJ, et al. Downregulation of several fibulin genes in prostate cancer. Prostate. 2007;67(16): $1770-1780$. 
40. $\mathrm{Hu} \mathrm{Z,} \mathrm{Ai} \mathrm{Q,} \mathrm{Xu} \mathrm{H,} \mathrm{et} \mathrm{al.} \mathrm{Fibulin-5} \mathrm{is} \mathrm{down-regulated} \mathrm{in} \mathrm{urothelial} \mathrm{car-}$ cinoma of bladder and inhibits growth and invasion of human bladder cancer cell line 5637. Urol Oncol. 2011;29(2):430-435.

41. Ohara H, Akatsuka S, Nagai H, et al. Stage-specific roles of fibulin-5 during oxidative stress-induced renal carcinogenesis in rats. Free Radic Res. 2011;45(2):211-220.

42. Tu K, Dou C, Zheng X, et al. Fibulin-5 inhibits hepatocellular carcinoma cell migration and invasion by down-regulating matrix metalloproteinase-7 expression. BMC Cancer. 2014;14:938.

43. Yi CH, Smith DJ, West WW, Hollingsworth MA. Loss of fibulin-2 expression is associated with breast cancer progression. Am J Pathol. 2007;170(5):1535-1545.

44. Law EW, Cheung AK, Kashuba VI, et al. Anti-angiogenic and tumorsuppressive roles of candidate tumor-suppressor gene, Fibulin-2, in nasopharyngeal carcinoma. Oncogene. 2012;31(6):728-738.

45. Alcendor DJ, Knobel S, Desai P, Zhu WQ, Hayward GS. KSHV regulation of fibulin-2 in Kaposi's sarcoma: implications for tumorigenesis. Am J Pathol. 2011;179(3):1443-1454.

46. Baird BN, Schliekelman MJ, Ahn YH, et al. Fibulin-2 is a driver of malignant progression in lung adenocarcinoma. PLoS One. 2013; 8(6):e67054.

47. Albig AR, Neil JR, Schiemann WP. Fibulins 3 and 5 antagonize tumor angiogenesis in vivo. Cancer Res. 2006;66(5):2621-2629.

48. Hu B, Thirtamara-Rajamani KK, Sim H, Viapiano MS. Fibulin-3 is uniquely upregulated in malignant gliomas and promotes tumor cell motility and invasion. Mol Cancer Res. 2009;7(11):1756-1770.
49. Hu B, Nandhu MS, Sim H, et al. Fibulin-3 promotes glioma growth and resistance through a novel paracrine regulation of Notch signaling. Cancer Res. 2012;72(15):3873-3885.

50. Nandhu MS, Hu B, Cole SE, Erdreich-Epstein A, Rodriguez-Gil DJ, Viapiano MS. Novel paracrine modulation of Notch-DLL4 signaling by fibulin-3 promotes angiogenesis in high-grade gliomas. Cancer Res. 2014;74(19):5435-5448.

51. Towner RA, Jensen RL, Vaillant B, et al. Experimental validation of 5 in-silico predicted glioma biomarkers. Neuro Oncol. 2013;15(12): $1625-1634$

52. Schwartz SA, Weil RJ, Thompson RC, et al. Proteomic-based prognosis of brain tumor patients using direct-tissue matrix-assisted laser desorption ionization mass spectrometry. Cancer Res. 2005;65(17): 7674-7681.

53. Kalinina J, Peng J, Ritchie JC, Van Meir EG. Proteomics of gliomas: Initial biomarker discovery and evolution of technology. Neuro Oncol. 2011;13(9):926-942.

54. Surowka AD, Adamek D, Szczerbowska-Boruchowska M. The combination of artificial neural networks and synchrotron radiation-based infrared micro-spectroscopy for a study on the protein composition of human glial tumors. Analyst. 2015;140(7):2428-2438.
OncoTargets and Therapy

\section{Publish your work in this journal}

OncoTargets and Therapy is an international, peer-reviewed, open access journal focusing on the pathological basis of all cancers, potential targets for therapy and treatment protocols employed to improve the management of cancer patients. The journal also focuses on the impact of management programs and new therapeutic agents and protocols on

\section{Dovepress}

patient perspectives such as quality of life, adherence and satisfaction. The manuscript management system is completely online and includes a very quick and fair peer-review system, which is all easy to use. Visit http://www.dovepress.com/testimonials.php to read real quotes from published authors. 